\title{
Н.В. ЛОПАТИНА, Г.А. ХАКИМОВА
}

\section{К ВОПРОСУ О ФАКТОРАХ СНИЖЕНИЯ ИНТЕРЕСА К ЧТЕНИЮ И БИБЛИОТЕКЕ В СОВРЕМЕННОМ ОБЩЕСТВЕ (НА ПРИМЕРЕ ФЕДЕРАТИВНОЙ РЕСПУБЛИКИ ГЕРМАНИИ)}

Проблема снижения читательской активности рассматривается как на уровне глобальных (информатизация, мировой финансовый кризис), так и на уровне национальных (локальные культурные трансформации) факторов культурного развития. Анализируется опыт библиотечного дела Германии в преодолении типовых и национальных проблем. Изучается влияние языковой реформы 1998 года на читательскую активность населения Германии. Ставится проблема влияния орфографического режима на сохранение письменного культурного наследия, на развитие книжной культуры.

Ключевые слова: библиотечное дело Германии, языковая реформа, чтение, книжная культура.

$\mathrm{B}$ последние годы особую остроту приобретает проблема снижения читательской активности вне зависимости от возраста, места проживания, сферы занятости. Обсуждение данной проблемы в широких кругах общественности, в том числе профессиональной и научной, позволяет говорить о невозможности сведения причин этого явления только к техническому прогрессу, однако комплекс культурологических, социальных, психологических, экономических причин, несомненно, связан с информатизацией. Вместе с тем, влияние информатизации не может и не должно рассматриваться столь прямолинейно, как сегодня. Это ведет к бытованию в общественном мнении оппозиции «компьютер - книжная культура» $и$, как следствие, приводит к концентрации действий библиотекарей, педагогов, управленцев именно на этом предмете. Информатизация как глобальный цивилизационный тренд затрагивает все стороны жизни современного общества и современного человека, создавая не только новую информационную среду как некий комплекс условий, но и трансформируя под влиянием этих условий базовые социальные институты и системы. Именно эти изменения катализируют отдельные культурные процессы и явления, которые в конечном итоге и определяют характер и особенности современных читательских практик во всем мире.

В данном случае речь идет об опосредованном влиянии информатизации на социальные системы и институты как на глобальном, так на локальном национальном уровне. В русле проводимых научных изысканий авторы сделали попытку выяснить влияние национального культурного фактора на процессы снижения читательской активности. Первоначальный посыл шел от сомнения в правомерности выводов о том, что проблемы чтения, книги и библиотек в современной России обусловлены исключительно падением духовности в результате политического и экономического краха великой державы.

Обращаясь к социологии и статистике чтения, издательского, книготоргового и библиотечного дела в России в первом - начале второго десятилетия XXI века
[1, с. $62-64 ; 2$, с. $131-164$ и др.], сопоставляя их с аналогичными данными по другим странам [3 и др.], исследователи были вынуждены отмечать сходный характер явлений и процессов в книжной культуре в разных экономических, политических и социокультурных условиях. Различные «вводные» позволяют предположить, что понимание социальной значимости книжной культуры, чтения, библиотеки в разных странах претерпевает изменения в силу причин, единых по сущности (экономических, политических, социальных, культурных, технологических) и отличных по содержанию. Признание глобализации цивилизационным трендом не может умалять роль региональных и национальных особенностей культурного развития, исторически обусловленных и устойчивых. В то же время глобализационные тенденции демонстрируют возможность культурных интервенций, рассеяния и социальной интеграции новаций в другую «культурную почву». В данной статье предлагается рассмотреть данное явление на примере библиотечного дела Германии.

В различные времена библиотечные практики Германии, ее книжная культура представляли огромный интерес для российских теоретиков и практиков, так как именно немецкая книжная культура открыла миру многие значимые явления и возможности и первой показала опыт их интеграции в традиционные условия: книгопечатание, книжные ярмарки, книготорговая библиография. Современный анализ опыта библиотечного дела Германии позволяет увидеть много нового и полезного для нынешних библиотек, с одной стороны, с точки зрения технологических новаций, а с другой стороны, с точки зрения преодоления типовых и национальных проблем [4].

Например, для организации библиотечного дела в условиях экономического кризиса или в иных сложных экономических условиях представляет интерес опыт распределенного финансирования немецких публичных библиотек. Наблюдается тенденция по сокращению бюджетов библиотек, или политика экономии, публичные книгохранилища получают недостаточные дотации от государства [5]. Проведенный Германским библиотечным 
союзом в 2012 году опрос среди сотрудников публичных библиотек о финансовой ситуации указывает на консолидацию бюджетов в $26 \%$ публичных библиотек и планирование их в 15,3\% библиотек. В 2011 г. этот показатель составил 33\% учреждений при 18\% библиотек, где эти мероприятия намечались. 21\% исследованных библиотек сообщают о сокращении их субсидий. В городах с более чем 100000 жителей каждая вторая библиотека вынуждена осуществлять мероприятия по консолидации бюджета [5]. Проблема сокращения бюджетных ассигнований коснулась библиотек в 2012 году в большей степени, чем в 2011 году (56\% библиотек по сравнению с 48\% в 2011 году). Более чем в половине этих учреждений происходит сокращение персонала или оно запланировано. Каждая четвертая публичная библиотека вынуждена сокращать количество проводимых мероприятий. 14,4\% библиотек вынуждены обходиться меньшим бюджетом для приобретения СМИ. 12\% исследованных библиотек должны были сократить время работы [5].

Основное финансовое бремя ложится на местные органы (зе́мли) с активным участием общинных и частных инвестиций, однако нельзя не отметить, что эффективность этих решений исторически обусловлена. Вместе с тем, отсутствие единой государственной политики в области организации библиотечного дела определило приоритетную роль общин в решении сущностных вопросов деятельности библиотеки. Рациональность в использовании ресурсов привела к расширению функций публичных библиотек, к выходящему за рамки базовых библиотечных функций использованию помещений, трансформации инструментов библиотечной педагогики. Между тем, в условиях децентрализации библиотек Германии и отсутствия единого Закона о библиотечном деле библиотечное обслуживание остается доступным для всех социальных групп немецкого общества, что оказывается более эффективным, чем привычные административные инструменты. Однако лишь «каждый десятый житель Германии регулярно пользуется библиотекой и берет на дом книги из абонемента. 20 миллионов заявляют, что рядом с их домом нет библиотеки» [6].

Анализ развития книжного рынка Германии демонстрирует общемировую тенденцию к снижению объема продаж традиционной бумажной книги и возрастающее внимание к электронной книге. Но даже с учетом диверсификации книги товарооборот книжного рынка не развивается столь интенсивно, как, например, в конце 80-х начале 90-х годов XX века, несмотря на то, что именно в Германии была сформирована социальная потребность в массовой книгопечатной книге как социокультурный феномен. По оценкам Биржевого союза немецкой книготорговли (Börsenverein des Deutschen Buchhandels), товарооборот книг и специальных журналов упал в 2011 году на 1,4\%, до 9,6 млрд евро. Товарооборот в розничной торговле книгами, согласно оценкам, снизился с 4,923 до 4,775 мрлд евро [3, с. 5]. Исследователи рынка Общества по изучению потребительского спроса (Gesellschaft für Konsumforschung - GfK) давали на 2012 год позитивные прогнозы, обозначив их девизом: «Желание покупать вместо разочарования от кризиса» [7, S. 9]. Однако весной 2012 года наблюдалось сокращение товарооборота даже в онлайн-торговле. Несмотря на это, книга по-прежнему остается у немцев популярнейшим подарком на РождеСтво ${ }^{1}$.

Публикации современных практиков библиотечного дела Германии позволяют не только фиксировать проблемы во взаимоотношениях ведущих акторов книжной культуры - издательств, книжной торговли и библиотек, но и задумываться о причинах такой социальной дисфункции: правовых лакунах информатизации (вопросы авторского права и лицензирования), отсутствии социальной ответственности в экономической политике (взвинчивание цен нанесло серьезный удар по бюджетам библиотек и вынудило их к аннулированию подписок, сокращению комплектования), социокультурных проблемах (столкновение социально-ориентированного и социально-педагогического подходов в библиотечном деле с финансово-ориентированным подходом в издательской деятельности и книжной торговле).

Анализ современных публикаций позволяет выявить позицию теоретиков и практиков библиотечного дела Германии относительно негативной динамики читательской активности населения страны. Во главу угла ставятся проблемы, обусловленные мировым финансовым кризисом. Вместе с тем, за пределами исследования остаются локальные социокультурные трансформации, с которыми связано развитие книжной культуры Германии в конце XX - начале XXI века: объединение Германии, слияниепоглощение политической, социальной и культурной систем, внутренняя культурная диффузия политических и культурных явлений в региональном аспекте и многое другое. В числе таких социокультурных трансформаций, оказавших влияние на культуру современной Германии, а следовательно, и на ее книжную культуру, следует назвать реформу немецкой орфографии 1996-2006 годов - одну из наиболее масштабных языковых реформ последнего столетия.

Системная взаимосвязь языковой и книжной культуры позволяет говорить, с одной стороны, о влиянии языковой реформы на библиотечное и издательское дело, с другой - о роли библиотечного и издательского дела в эффективной реализации языковых реформ и найти доказательство этому в опыте библиотечного и издательского дела немецкоязычного пространства. Современная информационная среда создает лучшие условия для наблюдения и анализа функционального разнообразия языка, чем информационная среда любого иного периода социокультурного развития. Интеграция средств социальной коммуникации, информационных массивов и потоков различного содержания и целевой ориентации позволяют увидеть и переоценить значение языка для традиционных

\footnotetext{
${ }^{1}$ Согласно опросу Торгового союза Германии (Handelsverband Deutschland - HDE), 32,5\% жителей Германии положили в 2011 году в качестве подарка под елку именно книгу [7, S. 7].
} 
социально-информационных институтов (социальных институтов, регулирующих информационно-коммуникативные процессы в обществе), например для институтов книжной культуры. Именно основные функции языка позволяют данным институтам осуществлять базовые для них виды деятельности и делать возможным расширение круга социальных задач, которые способны решать библиотеки, издательства и т. д. в новых социально-экономических и социально-культурных условиях. Невозможно рассматривать в отрыве друг от друга аккумулятивную функцию языка и кумулятивную, мемориальную функции библиотеки, реализующие хранение знания, сохранение письменного культурного наследия (материального, как книга, и нематериального, как тексты, идеи, языковые традиции и т. д.), предоставляющие возможность транслировать их во времени и оставлять в широком свободном доступе следующим поколениям. Именно благодаря такой функции языка как функция общения формируются информационно-документальные потоки и массивы, посредством которых издательства и библиотеки удовлетворяют информационные потребности, один из базовых видов потребностей современного человека.

Нынешний мир демонстрирует активную направленность на регулирование языкового развития. Одним из важнейших факторов языковых изменений выступает информатизация и необходимость кодирования информации на национальных языках, пользования универсальными средствами ввода информации на национальных языках для вхождения в глобальное информационное пространство. Это активизирует упрощение норм письменного языка, обновление орфографических режимов в русле освобождения от тех правил, которые теряют свою принципиальность для лингвистов и культурологов и перестают применяться массовым актором в повседневных культурных практиках.

Большинство современных культурологических и педагогических дискурсов молодежной культуры, субкультурных и новационных культурных течений и явлений концентрируются на устных формах языка. Изучается противостояние формальных речевых традиций и сленга, пиджина и других расхождений с официальными канонами, ставится проблема сохранения языка как важнейшего компонента национальной культуры. Вместе с тем, за пределами современных исследований оказывается проблема влияния орфографического режима на сохранение письменного культурного наследия, на развитие книжной культуры.

Западная культура, в целом следуя логоцентристской концепции, демонстрирует уверенность в том, что письменность вторична и лишь состоит на службе устной речи (например, так полагает Ф. Соссюр). Лишь отдельные исследователи, в частности Ж. Деррида, считают, что именно письменность реализует смыслоозначения как способ существования мира человека и человека в мире. Несмотря на то, что философское и культурное наследие Германии, а также вклад немецких постмодернистов [8] в понимание роли языка неоценим, учет влияния языковой политики на прикладные сферы, в частности, такие как, библиотечное дело, образование и т. д., не получил должного внимания в контексте прогнозирования или ретроспективного исследования причин и следствий снижения читательской активности, развития библиотек. Безусловно, нельзя преувеличивать значение этого фактора, однако и сбрасывать его со счетов невозможно.

Лингвисты Д. Нериус и Ю. Шарнхорст, вдумчиво изучавшие проблему кодификации и реформы немецкой орфографии, писали, что нацеленная на улучшение и упрощение орфография должна характеризоваться повышением систематики и более глубоким обобщением орфографических правил, устранением исключений и специальных правил, а также противоречий между универсальными и единичными правилами, в общем, большей определенностью и понятностью связей графической области по отношению к другим областям системы стандартного языка [9]. Реформа правописания, по выражению Д. Нериуса, «не ставит под угрозу постоянство письменной традиции или восприятие письменных продукций <...> Она - лишь маленький и порционный шаг к облегчению усвоения и применения орфографии. Она является также свидетельством того, что орфография часть живого и изменяющегося языка, которая не может долго существовать без развития» [10, S. 394].

Именно такое понимание реформы лежит в основе анализа ее влияния на книжную культуру и читательскую деятельность. Однако проблема заключается в том, что новые правила орфографии не были восприняты как норма значительной частью населения Германии и других немецкоязычных стран. В данном случае просматривается влияние серьезных социокультурных трансформаций, происходящих в обществе постмодерна. Общество крайне неоднозначно отнеслось к реформе немецкого правописания, в том числе наиболее активная полемика инициировалась интеллектуальной и творческой элитой: более 100 авторитетных представителей интеллигенции во главе с писателем Гюнтером Грассом - лауреатом Нобелевской премии - подписали «Франкфуртскую Декларацию» по реформе правописания. Среди первых подписавшихся были писатели Э. Хеншайд, В. Кемповский, Г. Кунерт, 3. Ленц, М. Вальзер, публицист и журналист Э.-Д. Луег, ведущий немецкого телевидения д-р Р. Виллемзен. К ним присоединились филологи, германисты, преподаватели немецкого языка, историки, книгоиздатели, библиотекари, журналисты и представители различных организаций.

Неоднородным было восприятие реформы и массовым актором². Одну из важных для социокультурного

\footnotetext{
2 Согласно опросам Института демоскопии г. Алленсбах (das Institut für Demoskopie Allensbach), в 1997 году 10\% немецкого населения в возрасте с 16 лет приветствовали реформу правописания, 70\% были против и $20 \%$ остались равнодушными. В ходе повторного опроса в 2000 году большинство немцев отклоняло реформу правописания. Только $13 \%$ из 2111 опрошенных указывали на то, что перешли на новое правописание. Следующий опрос населения в марте - апреле 2002 года дал следующие показатели: $56 \%$ были против реформы, $10 \%$ - за реформу, причем $57 \%$ не видели для себя причины перестраивать свое правописание, а 49\% требовали отмены реформы.
} 
анализа реформы немецкой орфографии тем, рассмотренных в трудах Ю. Хабермаса, образует теория демократии, теория публичности, взаимосвязь права и демократии [8]. Эта тема обсуждается Ю. Хабермасом в его книге «Фактичность и значимость», где развитое в предыдущих работах коммуникативное понятие разума применяется к классической теории суверенитета. Согласно Ю. Хабермасу, формирование национального суверенитета - рациональный процесс, включающий в себя выработку общественной воли, которая вне этой рациональной процедуры имела бы анархический характер.

Растянутый во времени, постепенный механизм реализации реформы с целью «мягкого» ее продвижения в массы базировался на бисистемном подходе, основанном на сосуществовании старой и новой языковой системы. Интерпретируя данные явления по Ю. Хабермасу [12], мы можем говорить об особом случае консенсуса как основы формирования суверенитета немецкой языковой культуры.

Особый интерес в данном контексте представляет реакция на реформу ведущих акторов книжной культуры - библиотек и издательств. Ориентированные на рынок издательства реализуют единообразие, и четкое соответствие нормам наблюдается только в изданиях официальных документов, учебной и детской литературы. Ориентируясь на свою целевую и читательскую аудиторию, в том числе на представителей третьего возраста и оппонентов реформы, большинство издательств (в частности, такие крупные издательства, как «Аксель Шпрингер АГ», «Франкфуртер Альгемайне цайтунг», «Зюддойче цайтунг», «Шпигель») сформировали собственные, так называемые «домашние» системы правописания, используя, в том числе, систему, созданную Союзом немецких информационных агентств, которая включает 1500 слов и сочетает старые и новые правила. Традиционно книга рассматривается как эталон культуры письменной речи, при этом любой плюрализм отвергается в силу особой значимости правил орфографии. Языковое планирование, отражая динамику языка, всегда ориентировано на создание новых орфографических правил как устойчивых и непререкаемых языковых норм. Идея упорядочения орфографии находит свое выражение в изживании вариативности; разногласия касаются вопроса о целесообразности одномоментного либо постепенного избавления от орфографических вариантов [13].

В июле 2004 года телевизионный журнал «Панорама» (Panorama) опубликовал свои исследования настроения общественности по отношению к реформе орфографии, и оказалось, что 77\% немцев считали реформу по прошествии шести лет после ее введения «нецелесообразной». Только каждый пятый гражданин Германии (21\%) оценил реформу положительно. В 2008 году Институт демоскопии г. Алленсбах провел повторный опрос среди 1820 лиц в возрасте с 16 лет на тему «Немецкий язык» в самом широком смысле слова, в том числе и по вопросам реформы правописания. 55\% опрошенных выступили против реформы, для 31\% реформа была безразлична, и только 9\% были за нее. 79\% всех участвовавших в опросе согласились с мнением, что из-за реформы правописания при написании многих слов не знаешь теперь, как они пишутся. Среди сторонников реформы этот показатель составил 54\% [11].
Библиотекари первоначально высказывали небезосновательные опасения относительно разрушения языковой традиции, сбоя привычной траектории культурного развития и, как следствие, потрясения культуры чтения, а также трудностей перестройки и чрезмерных расходов, связанных с актуализацией фондов. Несмотря на законодательный характер языковой реформы, официально открытое ее публичное обсуждение, определенный порядок ее введения в официальные и повседневные языковые практики, в том числе в систему образования, библиотекари не были обеспечены регламентами и руководствами по реформированию фондов, организации каталогов, работе с читателями в таких условиях. Наибольшие трудности испытывали школьные и детские библиотеки, перед которыми была поставлена задача полной замены фондов. Один из наиболее ярких немецких лингвистов, выступающий в оппозиции реформе, лингвист Теодор Иклер эмоционально и выразительно охарактеризовал этот процесс следующим образом: «Уничтожено, отсортировано, отправлено в изгнание». В одноименной статье, вызвавшей широкий резонанс в немецком обществе, Т. Иклер говорит о том, что «сравнимых потерь не было со времен Фридриха» [14, S. 31]. И в данном случае политика издательств, поведение значимых современных авторов выстроили барьеры в библиотечном обслуживании и культурном развитии подрастающего поколения.

Проведенное авторами данной статьи летом 2012 года социологическое исследование немецких читателей, проживающих в Мюнхене, показало устойчивое нежелание значительной группы читателей третьего возраста досугового чтения текстов в новой орфографии, что является одним из ориентиров немецкоязычного книжного рынка. Респонденты 25-35 лет, а также родители, чьи дети учились в школе в начальный период реформы, вспоминали проблемы ликвидации фондов и пустых полок в детских библиотеках, ожидание переиздания лучших образцов детской литературы, вынужденное обращение к «запрещенной» для школьников орфографии для приобщения детей к чтению в семье. Вместе с тем, в настоящий момент данная группа читателей уже забыла о реформе и поглощена другими проблемами книжной культуры, в частности проблемами электронных книг. Это подтверждает позицию лингвистов о том, что любое слово должно иметь одно-единственное написание, а орфографическая вариативность - явление избыточное, создающее излишнюю неразбериху [13].

Таким образом, можно говорить о том, что системная взаимосвязь языка и книжной культуры определяют влияние языковой политики на поведение акторов книжной культуры (издательств, библиотек, авторов, читателей, книжной торговли, науки), изменений языковых норм на читательскую активность. Опыт развития книжной культуры Германии в условиях языковой реформы ставит принципиальный вопрос: целесообразно адаптироваться к подобным трансформациям, воспринимая их как неукоснительную норму, либо надо быть агентом подобных 
трансформаций, создавая своего рода консорциум социальных институтов, способных снизить риски культурных шоков. Подводя итог вышесказанному, необходимо отметить, что «немецкая модель» языковой реформы отличается отсутствием телеологического и стратегического единства акторов книжной культуры, что позволяет увидеть «плюсы и минусы» данного выбора и учесть этот опыт в деятельности библиотек и других акторов в условиях языковых реформ.

\section{Список литературы}

1. Дубинин Б.В. Чтение в России - 2008. Тенденции и проблемы (научные проекты, исследования) // Вестник Библиотечной Ассамблеи Евразии. - 2009. - № 2.

2. Чудинова В.П. Детское чтение. Негативные последствия развития медиасреды // Дети и культура. - М.: Комкнига, 2007.

3. И снова Запад нам в пример // Чтение. Общество. Государство: Материалы к Всероссийскому Конгрессу в поддержку чтения. - М.: СИРПП, 2001.

4. Зефельдт Ю., Сире Л. Двери в прошлое и будущее - библиотеки в Германии [Электронный ресурс]. — Режим доступа: http://www.goethe.de/kug/pro/ifla/russisch.pdf

5. Zahlen und Fakten. Bericht zur Lage der Bibliotheken 2012 [Электронный ресурс]. - Режим доступа: http://www.
bibliotheksverband.de/fileadmin/user_upload/DBV/themen/ DBV_Bericht_2012.pdf

6. Арнольд И. Идеальная библиотека [Электронный ресурс]. - Режим доступа: www.dw.de/идеальнаябиблиотека/а-1037547

7. Buch und Buchhandel in Zahlen 2012, Herausgeber: Börsenverein des Deutschen Buchhandels e. V. — Frankfurt am Main, 2012.

8. Хабермас Ю. Демократия. Разум. Нравственность. - М.: Академия, 1995.

9. Nerius D., Scharnhorst J. Theoretische Probleme der deutschen Orthographie. - Berlin, 1980.

10. Nerius D. Beiträge zur deutschen Orthographie. Hrsg. Von Petra Ewald und Bernd Skibitzki anlässlich des 65.Geburtstages von Dieter Nerius. - Frankfurt am Main; Berlin; Bern; Bruxelles; New York; Oxford; Wien: Lang, 2000.

11. Allensbacher Berichte. 2002. Nr. 7 [Электронный ресурс]. Режим доступа: http://www.ifd-allensbach.de/uploads/.../ prd_0207.pd

12. Хабермас Ю. Теория коммуникативного действия // Вестник МГУ. - Сер. 7. - Философия. - 1994. — № 4.

13. Нечаева И.В. Что такое орфографические варианты и почему они появляются в языке [Электронный ресурс]. Режим доступа: http://www.gramma.ru/RUS/?id=1.85

14. Ickler T. Ausgemistet, aussortiert, exiliert // Frankfurter Allgemeiner Zeitung, Feuilleton. 2009. 29 0ktober [Электронный ресурс]. - Режим доступа: http://fact-fiction. net $/ \mathrm{p}=3166$

удк 019.911:[008+7]

ББК 91.9:79/85

\section{И.В. БАБИЧ}

\section{ЭВОЛЮЦИЯ СОЦИАЛЬНОЙ РОЛИ ТЕКУЩЕЙ БИБЛИОГРАФИИ ПО КУЛЬТУРЕ НА РУБЕЖЕ ВЕКОВ}

Текущая библиография по культуре и искусству рассматривается как периодическое издание в контексте эволюции представлений о задачах и нормах научно-информационной и собственно научной деятельности, а также высшего образования. Кратко прослежена история издания текущих библиографических указателей по культуре и искусству в Российской государственной библиотеке (1973-2013 гг.). Сделан акцент на том, что доступ к изданиям обеспечивается не только техническими средствами, но и отработанной системой представления информационного потока и содержательного поиска, средством которого является текущая отраслевая библиография.

Ключевые слова: текущая библиография, информационный фон, бумажные библиографические издания, информатизация библиографической деятельности, доступность литературы по культуре и искусству, использование библиографии.

$\mathrm{T}$ екущая тематическая библиография обладает всеми признаками периодического издания, однако стоит в этом ряду особняком и не всегда воспринимается как таковое. Система текущих библиографических изданий по культуре и искусству появилась в Российской государственной библиотеке, а тогда - Ленинке, на первой волне информатизации, примерно в ту же эпоху, когда в
Советском Союзе создавались ИНИОН, ВИНИТИ и другие информационные институты и службы ${ }^{1}$.

По форме эта система была вполне традиционной - тематические указатели посвящены библиотечно-

\footnotetext{
Издающий эту библиографию Научно-информационный центр по культуре и искусству (Информкультура) был создан в Государственной библиотеке им. В.И. Ленина в 1972 году.
} 